\title{
Anemia: A Diagnostic Malady in Management of Dengue Patients
}

\author{
Nabila Afsar, Sabahat Zamani Nagma and Idrees Akhtar Afroze* \\ Department of Pathology, Deccan College of Medical Sciences, Hyderabad, Telengana
}

\begin{abstract}
Background: With the high prevalence of anemia and increasing incidence of dengue in developing countries like India, diagnosis of anemia in dengue patients needs to be stressed. There is higher hemoglobin and hematocrit as a result of plasma leakage in dengue; hence diagnosis and treatment of anemia may be missed.

Methods: A retrospective study was done on 138 dengue patients diagnosed in 2017, in a tertiary care teaching hospital in Hyderabad. The complete blood counts and blood picture data was retrieved and statistical analysis was performed using Microsoft Excel.

Result: $60 \%$ of patients $>5$ yrs of age showed low hemoglobin while $93.3 \%$ showed hypochromia. In patients aged 5-11yrs and $12-14$ yrs, $31.4 \%$ and $14.3 \%$ respectively had low hemoglobin, but hypochromia was noted in $48.6 \%$ and $57.1 \%$.In non pregnant females, $68.4 \%$ showed low hemoglobin while 55.3\% showed hypochromia. In males, $25 \%$ showed low hemoglobin whereas $13.9 \%$ showed hypochromia.

Wide variability in hemoglobin concentration of same patient was noted with coefficient of variation above $1 \%$ in $91.7 \%$ of cases. MCV and $\mathrm{MCH}$ had coefficient of variation more than $1.1 \%$ and $0.5 \%$ in $25 \%$ and $69.4 \%$ of cases respectively.

Conclusion: Mean corpuscular volume is a stable parameter which can be used to assess the morphological status of the RBC even in a background of hemoconcentration where the hemoglobin is spuriously raised. The importance of inclusion of red cell indices especially mean corpuscular volume in complete blood counts reports is stressed.
\end{abstract}

\section{Keywords: Dengue, Anemia, Hemoglobin variation, $M C V$, red cell indices}

\section{Introduction}

Dengue is an infection caused by dengue virus transmitted by the bite of an infected female mosquito. 50 million people worldwide suffer with dengue annually. ${ }^{[1]}$ In India, the dengue incidence sharply increased from 1998 to 2001 from 0.72 to 3.21 per million population. In 2003, 2005, 2006, 2008 and 2009, the dengue incidence exceeded 10 per million population. Since 2010 , a dengue incidence of greater than 15 per million population has been reported annually ${ }^{[2]}$.

Anemia, defined as a reduction in hemoglobin $(\mathrm{Hb})$ concentration, red-cell count, or packed-cell volume below established cut-off levels, is a widely discussed public health challenge that India is facing ${ }^{[3]}$. According to the World Health Organization (WHO), anemia among women is defined as a hemoglobin concentration of $<120$ $\mathrm{g} / \mathrm{L}$ for non-pregnant women aged 15 years and above, and a hemoglobin concentration of $<110 \mathrm{~g} / \mathrm{L}$ for pregnant women and $<130 \mathrm{~g} / \mathrm{L}$ in $\mathrm{men}^{[4]} .53 \%$ of all women have anemia as per the National Family Health Survey 20152016, and the 2017 National Health Policy tabled by the Ministry of Health and Family Welfare, Government of India, acknowledges this high burden of anemia ${ }^{[5]}$. The estimated prevalence of anemia in developing countries is $39 \%$ in children $<5$ years, $48 \%$ in children $5-14$ years, $42 \%$ in women $15-59$ years, $30 \%$ in men $15-59$ years, and $45 \%$ in adults $>60$ years $^{[6]}$.

With the high prevalence of anemia and increasing incidence of dengue in developing countries like India, the importance of dengue association with anemia and the diagnosis of anemia in such patients need to be stressed. It is a known fact that dengue patients had higher hemoglobin levels and a higher hematocrit as a result of the plasma leakage. An in vitro study revealed a cross-reaction of proinflammatory mediators such as tumor necrosis factor (TNF)-alpha and anti-NS1 antibodies with surface proteins on endothelial cells causing apoptosis of these cells and subsequently plasma leakage ${ }^{[7]}$. Higher hemoglobin levels due to hemoconcentration may lead to false notion of normal hemoglobin content and hence, the diagnosis and treatment of anemia may be missed in these patients who can otherwise rarely undergo routine investigations due to lack of resources. Further, the possibility of cardiac volume overload due to uninhibited fluid transfusion in an already anemic patient needs to be checked. The study was conducted to observe the patterns of red cell parametres and their variability in dengue patients. 


\section{Materials and Methods}

A hospital based retrospective study was done on 138 patients diagnosed with dengue fever during the year 2017, in a tertiary care teaching hospital in Hyderabad, after ethical clearance was obtained from the institutional ethical committee. The sample size was calculated to be 96 using the creative research system survey software ${ }^{[8]}$ at $95 \%$ confidence level and $38.3 \%$ prevalence of dengue in India ${ }^{[9]}$, with a confidence interval of 10 . After routine informed consent from patient, $2 \mathrm{ml}$ venous blood was collected from antecubital vein under aseptic conditions in a $\mathrm{K}_{2}$ EDTA vacutainer. Samples were processed immediately on Horiba ES60 automated 5 part differential cell counter. Peripheral smears were prepared and stained with Leishman's stain for all samples. The smears were examined by pathologist on rotational duty and results were recorded in a register routinely. The complete blood count $(\mathrm{CBC})$ data was retrieved from cell counter with special emphasis on hemoglobin( $\mathrm{Hb})$, hematocrit(HCT), mean corpuscular volume(MCV), mean corpuscular hemoglobin $(\mathrm{MCH})$. Peripheral smear data was retrieved from registers.

Inclusion Criteria: All NS1 antigen positive patients diagnosed at our hospital during the year 2017 were included in the study. All the patients who had 3 or more reports of $\mathrm{CBC}$ including peripheral smear findings were further subdivided to assess the coefficient of variation in gyeach subsequent report of the patients.

Exclusion criteria: Patients with negative NS1Ag and only IgG positivity, pregnant females (to exclude physiological anemia), infants less than 6 months (maternal antibodies confers protection).

Statistical Analysis was done on Microsoft Excel and the percentage, mean, standard deviation and coefficient of variation was calculated. The acceptable coefficient of variation of the cell counter was first established by multiple successive reruns of normal biological samples and was determined to be $1 \%$ for $\mathrm{Hb}, 1.1 \%$ for $\mathrm{MCV}$ and $0.5 \%$ for $\mathrm{MCH}$.

\section{Result}

Table 1 shows that the patients' age ranged from 6 months to 80 years, with majority of cases under 30 years with both genders being involved almost equally $(50.7 \%$ males and $49.3 \%$ females). All the cases were subdivided according to the age and gender as per WHO criteria for diagnosis of anemia.

The $\mathrm{Hb}$ ranged from 4.6-18.1 g/dl in the 138 cases. Mean $\mathrm{Hb}$ was $12.05 \mathrm{~g} / \mathrm{dl}$. Table 2 depicts the incidence of low $\mathrm{Hb}$ by cell counter analysis and the incidence of hypochromia on peripheral blood smear examination in different age groups divided as per WHO criteria and in both genders.

In the age group 6 months to under 5 yrs, it was noted that $60 \%$ of the cases showed $\mathrm{Hb}$ less than the cut off indicating anemia, while $40 \%$ had normal $\mathrm{Hb}$ values. However, the percentage of cases showing hypochromia on smear was much higher $(93.3 \%)$ indicating a spuriously raised $\mathrm{Hb}$ value in $33.3 \%$ of cases.

In the age groups 5-11yrs and 12-14 yrs, 31.4\% and 14.3\% respectively had $\mathrm{Hb}$ less than the WHO cutoff indicating anemia. However, hypochromia was noted in $48.6 \%$ and $57.1 \%$ which again indicates a spurious raise in $\mathrm{Hb}$ in $17.2 \%$ and $42.8 \%$ of the cases respectively.

In non pregnant females, majority (68.4\%) showed $\mathrm{Hb}$ values hinting at anemia while around $55.3 \%$ cases showed actual hypochromia, indicating either presence of normocytic normochromic anemia in females of menstruating age group or a spuriously low $\mathrm{Hb}$ due to fluid transfusions as therapeutic intervention in dengue.

In males, the overall incidence of anemia was less with $25 \%$ of the cases showing $\mathrm{Hb}$ values less than the cut off whereas $13.9 \%$ of the males showed actual hypochromia, suggesting hemodilution and a spuriously low $\mathrm{Hb}$ in $11.1 \%$ of cases.

Table 3 shows the mean, standard deviation(SD) and coefficient of variation $(\mathrm{CV})$ of $\mathrm{HB}, \mathrm{MCV}$ and $\mathrm{MCH}$ in a total of 36 patients $(26 \%)$ out of the 138 patients who had 3 or more reports for consecutive monitoring. An analysis was done to demonstrate the variation in $\mathrm{Hb}, \mathrm{MCV}$ and $\mathrm{MCH}$ values of the same patient on different days of the disease during the course of treatment, depending on the hydration due to fluid therapy or the hemoconcentration due to leakage of intravascular fluid into the extracellular compartment as pathognomic of dengue. The CV of the cell counter was first established by multiple successive reruns of a normal biological sample and was determined to be $1 \%$ for $\mathrm{Hb}, 1.1 \%$ for $\mathrm{MCV}$ and $0.5 \%$ for $\mathrm{MCH}$. It was noted that there was wide variability in the $\mathrm{Hb}$ concentration of the same patient on different days with $\mathrm{CV}$ above $1 \%$ in $91.7 \%$ of the cases. MCV had remained constant with 75 percentile of cases having $\mathrm{CV}$ less than the established $\mathrm{CV}$ for the cell counter.

\section{Discussion}

The present study was designed to highlight the effect of dengue associated changes in $\mathrm{Hb}$ and red cell indices in a country plagued by anemia and the importance of anemia to be diagnosed immediately even in the background of hemoconcentration which tends to give spuriously high $\mathrm{Hb}$ values and a false sense of absence of anemia. Once these 
Table 1: Patient Demographics according to WHO cut off for diagnosis of anemia.

\begin{tabular}{|l|c|c|c|}
\hline Age & $\begin{array}{c}\text { Male } \\
\mathbf{n}=70(\%)\end{array}$ & $\begin{array}{c}\text { Female } \\
\mathbf{n = 6 8 ( \% )}\end{array}$ & $\begin{array}{c}\text { Total } \\
\mathbf{N}=138(\%)\end{array}$ \\
\hline $6 \mathrm{M}-<5$ YRS & $7(10 \%)$ & $8(11.7 \%)$ & $15(10.8 \%)$ \\
\hline $5-11$ & $18(25.7 \%)$ & $5(25 \%)$ & $14(25.3 \%)$ \\
\hline $12-14$ YRS & $9(12.8 \%)$ & $38(55.8 \%)$ & $38(27.5 \%)$ \\
\hline NON PREGNANT FEMALES & - & - & $36(26 \%)$ \\
\hline MALES & $36(51.4 \%)$ & & $1 \%)$ \\
\hline
\end{tabular}

Table 2: Hemoglobin levels and hypochromia in Dengue cases.

\begin{tabular}{|l|l|l|l|l|l|l|}
\hline AGE & $\begin{array}{l}\text { TOTAL } \\
\text { NO OF } \\
\text { CASES(N) }\end{array}$ & $\begin{array}{l}\text { HB CUT OFF } \\
\text { POINT } \\
\text { g/dl }\end{array}$ & $\begin{array}{l}\text { NO OF CASES } \\
\text { WITH HB } \\
\text { <CUT OFF } \\
\text { (AGE-GENDER } \\
\text { RELATED) } \\
\text { (AGE-GENDER }\end{array}$ & $\begin{array}{l}\text { NO OF CASES } \\
\text { WITH HB } \\
\text { >CUT OFF } \\
\text { RELATED) }\end{array}$ & $\begin{array}{l}\text { NO OF } \\
\text { CASES WITH } \\
\text { HYPOCHROMIA }\end{array}$ & $\begin{array}{l}\text { WO OF CASES } \\
\text { HITHOUT }\end{array}$ \\
\hline 6 m to <5 YRS & 15 & 11 & $60 \%)$ & $6(40 \%)$ & $14(93.3 \%)$ & $1(6.7 \%)$ \\
\hline $5-11$ YRS & 35 & 11.5 & $11(31.4 \%)$ & $24(68.6 \%)$ & $17(48.6 \%)$ & $18(51.4 \%)$ \\
\hline $12-14$ YRS & 14 & 12 & $2(14.3 \%)$ & $12(85.7 \%)$ & $8(57.1 \%)$ & $6(42.9 \%)$ \\
\hline Non pregnant female & 38 & 12 & $26(68.4 \%)$ & $12(31.6 \%)$ & $21(55.3 \%)$ & $17(44.7 \%)$ \\
\hline Males & 36 & 13 & $9(25 \%)$ & $27(75 \%)$ & $5(13.9 \%)$ & $31(86.1 \%)$ \\
\hline TOTAL & 138 & & $\mathbf{5 7 ( 4 1 . 3 \% )}$ & $\mathbf{8 1 ( 5 9 . 7 \% )}$ & $\mathbf{6 5}(\mathbf{4 7 . 1} \%)$ & $\mathbf{7 3 ( 5 2 . 8 \% )}$ \\
\hline
\end{tabular}

Table 3: Mean, SD and CV of HB, MCV and MCH of patients with 3 or more reports.

\begin{tabular}{|c|c|c|c|c|c|c|c|c|c|c|c|c|c|c|c|c|c|c|c|}
\hline & & \multicolumn{18}{|c|}{ Patient S.no } \\
\hline & & 1 & 2 & 3 & 4 & 5 & 6 & 7 & 8 & 9 & 10 & 11 & 12 & 13 & 14 & 15 & 16 & 17 & 18 \\
\hline \multirow[t]{3}{*}{$\mathrm{Hb}$} & Mean(g/dl) & 11.7 & 12.9 & 12.2 & 12.5 & 11.5 & 10.9 & 11.7 & 13.2 & 11.9 & 12.8 & 11.5 & 13.3 & 12.9 & 10.9 & 12.2 & 12.4 & 16.3 & 13.4 \\
\hline & SD & 0.25 & 1.3 & 0.8 & 0.2 & 0.7 & 0.8 & 0.7 & 1.2 & 2.3 & 0.2 & 0.86 & 0.45 & 0.5 & 0.3 & 0.1 & 0.5 & 1.14 & 0.65 \\
\hline & CV (\%) & 2 & 10 & 6 & 1 & 5 & 7 & 5 & 9 & 19 & 1 & 7 & 3 & 3 & 3 & 0.8 & 4 & 7 & 4 \\
\hline \multirow[t]{3}{*}{ MCV } & Mean(fl) & 84 & 80 & 82.6 & 82 & 77 & 66 & 81.5 & 81.5 & 83.6 & 87.6 & 78 & 79.5 & 83.3 & 78.3 & 78.6 & 83 & 95.6 & 82 \\
\hline & SD & 0 & 1.7 & 0.5 & 0 & 1.7 & 0 & 0.6 & 0.8 & 0.6 & 0.6 & 0 & 0.6 & 0.6 & 1.2 & 1.5 & 1 & 0.5 & 0 \\
\hline & CV(\%) & 0 & 2 & 0.6 & 0 & 2 & 0 & 0.6 & 1 & 0.6 & 1 & 0 & 0.6 & 0.6 & 0.1 & 0.1 & 1 & 0.5 & 0 \\
\hline \multirow[t]{3}{*}{$\mathrm{MCH}$} & Mean (pg) & 28.2 & 26.7 & 27.5 & 27.1 & 26.1 & 21.3 & 27.2 & 27.1 & 28.1 & 28.4 & 25 & 26.4 & 27 & 25.5 & 26.6 & 27.7 & 32.1 & 27.1 \\
\hline & SD & 0.3 & 0.2 & 0.2 & 0.3 & 0.2 & 0.2 & 0.2 & 0.1 & 0.2 & 0.4 & 0.8 & 0.1 & 0.3 & 0.2 & 0.2 & 0.3 & 0.4 & 0.6 \\
\hline & CV(\%) & 1 & 0.8 & 0.5 & 1 & 0.9 & 0.5 & 0.9 & 0.4 & 0.8 & 1 & 2 & 0.4 & 0.9 & 0.7 & 0.8 & 1.2 & 0.1 & 0.9 \\
\hline
\end{tabular}

\begin{tabular}{|c|c|c|c|c|c|c|c|c|c|c|c|c|c|c|c|c|c|c|c|}
\hline & & \multicolumn{18}{|c|}{ Patient S.no(contd) } \\
\hline & & 19 & 20 & 21 & 22 & 23 & 24 & 25 & 26 & 27 & 28 & 29 & 30 & 31 & 32 & 33 & 34 & 35 & 36 \\
\hline \multirow[t]{3}{*}{$\mathrm{Hb}$} & Mean(g/dl) & 11.3 & 10.5 & 15.1 & 8 & 10.5 & 13.9 & 15 & 16.2 & 14.3 & 15.2 & 15.3 & 15.4 & 10 & 8 & 10.2 & 8.4 & 12.2 & 10 \\
\hline & SD & 1.3 & 0.6 & 15.1 & 0.3 & 1.1 & 0.6 & 0.4 & 0.7 & 1.1 & 1 & 0.5 & 0.41 & 0.9 & 0.4 & 0.4 & 0.4 & 0.6 & 0.7 \\
\hline & CV(\%) & 11 & 5 & 0.3 & 3 & 10 & 4 & 2 & 4 & 7 & 6 & 2 & 2 & 9 & 4 & 3 & 4 & 4 & 6 \\
\hline
\end{tabular}




\begin{tabular}{|c|c|c|c|c|c|c|c|c|c|c|c|c|c|c|c|c|c|c|c|}
\hline & & \multicolumn{18}{|c|}{ Patient S.no(contd) } \\
\hline & & 19 & 20 & 21 & 22 & 23 & 24 & 25 & 26 & 27 & 28 & 29 & 30 & 31 & 32 & 33 & 34 & 35 & 36 \\
\hline \multirow[t]{3}{*}{ MCV } & Mean(fl) & 99.2 & 72.6 & 2 & 66.6 & 77.3 & 87.5 & 88.3 & 81.5 & 86.6 & 83.6 & 83.3 & 91 & 108.3 & 59.8 & 73.6 & 73 & 81.6 & 76.7 \\
\hline & SD & 0.8 & 1.5 & 87.5 & 2.5 & 0.6 & 3.5 & 0.6 & 0.5 & 1.5 & 0.6 & 0.6 & 0 & 3.8 & 0.9 & 0.6 & 2 & 0.6 & 0.8 \\
\hline & CV(\%) & 0.8 & 2 & 0.6 & 3 & 0.7 & 0.4 & 0.6 & 0.6 & 1.7 & 0.6 & 0.1 & 0 & 3 & 1 & 0.7 & 2 & 0.7 & 1 \\
\hline \multirow[t]{3}{*}{ MCH } & Mean (pg) & 33.1 & 23.2 & 28.7 & 20.9 & 24.2 & 29.8 & 29.9 & 27.3 & 29.7 & 29.2 & 28.1 & 29.7 & 34.6 & 18.4 & 23.1 & 23.2 & 27.3 & 25 \\
\hline & SD & 0.4 & 0.2 & 0.2 & 0.4 & 0.1 & 0.2 & 0.4 & 0.1 & 0 & 0.4 & 0.2 & 0.3 & 1.7 & 0.4 & 0.2 & 0.2 & 1.4 & 0.3 \\
\hline & CV(\%) & 0.1 & 1 & 0.6 & 0.1 & 0.4 & 0.8 & 0.1 & 0.2 & 0 & 1.1 & 0.5 & 0.9 & 4 & 2 & 0.8 & 0.8 & 5 & 1 \\
\hline
\end{tabular}

cases are rehydrated, the $\mathrm{Hb}$ collapses to the original value creating diagnostic maladies and therapeutic inadequacies.

Previous studies have highlighted the fact that patients with dengue fever develop hemoconcentration. In a study by Mogra et al, it was observed that $41 \%$ of children suffering from dengue showed hemoconcentration ${ }^{[10]}$. In another study conducted by Chaloemwong et al, the dengue group had higher hemoglobin levels than the control group from day 3 to day 10. The highest value of hemoglobin was observed on day 7 of the fever: The dengue group had higher hemoglobin levels and a higher hematocrit as a result of the plasma leakage ${ }^{[11]}$. These findings were in agreement with the present study. The pathogenesis has been explained by an in vitro study which revealed a cross-reaction of proinflammatory mediators such as tumor necrosis factor (TNF)-alpha and anti-NS1 antibodies with surface proteins on endothelial cells causing apoptosis of these cells and subsequently plasma leakage ${ }^{[12]}$.

In the present study, $68.4 \%$ of non pregnant females had $\mathrm{Hb}$ values hinting at anemia while around $55.3 \%$ cases showed actual hypochromia, indicating either presence of normocytic normochromic anemia in females of menstruating age group or a spuriously low $\mathrm{Hb}$ due to fluid transfusions as therapeutic intervention in dengue. Whereas in male patients, the overall incidence of anemia was less with $25 \%$ of the cases showing $\mathrm{Hb}$ values less than the cut off while $13.9 \%$ of the males showed actual hypochromia, suggesting hemodilution and a spuriously low $\mathrm{Hb}$ in $11.1 \%$ of cases . This may be explained by the reason that patients may have already received basic management including intravenous fluid therapy in the primary care setting before presenting to our tertiary care hospital. Ralapanawa et al. inferred that the decline of the mean value may be due to the fluid management in the ward where given fluid quotas may have caused some dilution of the plasma ${ }^{[13]}$. The possibility of volume overload needs to be checked in such patients.

In another study by Kaur Ratandeep et al, it was observed that the $\mathrm{Hb}$ levels are low due to disseminated intravascular coagulation (DIC), where chemicals responsible for clotting are used up and lead to risk of severe bleeding ${ }^{[14]}$. In a study by Shamsundar $\mathrm{K}$, hemoglobin $(\mathrm{Hb})$ ranged from $6 \mathrm{gm} \%-17.9 \mathrm{gm} \%{ }^{[15]}$.In the study by Meena, et al hemoglobin ranged from 7.5-17.5 g/dl, mean hemoglobin value was $12.6 \mathrm{~g} / \mathrm{dl}^{[16]}$. Dongre, et al. observed hemoglobin level from $3.6 \mathrm{gm} / \mathrm{dl}$ to $16.7 \mathrm{gm} / \mathrm{dl}$ with a mean of $11.9 \mathrm{gm} /$ $\mathrm{dl}^{[17]}$.In the present study, $\mathrm{Hb}$ ranged from 4.6-18.1 g/dl and mean $\mathrm{Hb}$ was $12.05 \mathrm{~g} / \mathrm{dl}$.

In a study by Tanmay K. Mehta, decreased hemoglobin< $11 \mathrm{gm} / \mathrm{dl}$ is noted in $59.59 \%$ of dengue cases. $61.7 \%$ of total dengue showed MCV within normal range of 80 to 90 fl $.77 .88 \%$ of total dengue showed decreased $\mathrm{MCH}$ value of less than $27.5 \mathrm{pg}{ }^{[18]}$. In the present study, the cut off for $\mathrm{MCV}$ and $\mathrm{MCH}$ was age based hence it was observed that $36 \%$ of the group 1 patients had $\mathrm{MCV}<75 \mathrm{fl}$ and $38.7 \%$ of group 2 patients had $\mathrm{MCV}<81 \mathrm{fl}$. $\mathrm{MCH}$ was $<25 \mathrm{pg}$ in $50 \%$ of group 1 patients and $<27 \mathrm{pg}$ in $19 \%$ of the group 2 patients.

Francisca Raimunda et al observed that for the group aged 15 years or over with classical dengue, there was a greater variation in $\mathrm{Hb}$ in the course of the disease and for dengue hemorrhagic fever(DHF), a greater variation of $\mathrm{Hb}$ was noted which was most evident from the 4th to 6th days. It was concluded that only DHF showed peak elevations in $\mathrm{Hb}$ and Hct during the course of the disease, a change most likely attributed to hemoconcentration, which can lead to hypovolemic shock ${ }^{[19]}$. The same findings were echoed in the present study wherein $\mathrm{Hb}$ and $\mathrm{MCH}$ showed a high coefficient of variation compared to $\mathrm{MCV}$ which was relatively stable through the course of the disease. This finding suggests that $\mathrm{MCV}$ is a more reliable indicator of the red cell status of the patient suffering from dengue fever since it is calculated directly from the entire $\mathrm{RBC}$ histogram. The variation in $\mathrm{MCH}$ could be either due to the narrow range of the established $\mathrm{CV}$ or due to effect of $\mathrm{Hb}$ value as $\mathrm{MCH}$ is calculated from the $\mathrm{HB}$ value and the $\mathrm{RBC}$ count, both of which are subject to variation in cases with heamoconcentration and hemodilution. 
The present study did not include pregnant females as there is physiological anemia and increase in plasma volume ${ }^{[20] .}$ Infants less than 6 months were also excluded as maternal antibodies protect infants from dengue infection ${ }^{[21]}$.

Further, there is evidence that iron deficiency in human population might contribute to the vectorial permissiveness to dengue virus, thereby facilitating its spread by mosquitoes. This finding suggests that diagnosis of anemia in dengue patients is important in the prevention of dengue spread and iron supplementation could reduce dengue transmission in endemic areas ${ }^{[22]}$.

\section{Conclusion}

In a country where anemia is highly prevalent, the possibility of missing diagnosis of anemia in patient suffering from dengue fever due to hemoconcentration becomes a major issue. $\mathrm{Hb}$ and $\mathrm{PCV}$ analysis were only useful to monitor the level of hemoconcentration and subsequent raised $\mathrm{Hb}$ and PCV which is a hallmark of complications by dengue fever. $\mathrm{MCV}$ is a stable parameter which can be used to assess the morphological status of the RBC and is useful to diagnose anemia even in a background of hemoconcentration. Further, the complication of volume overload needs to be avoided in an anemic patient suffering from dengue by stringent monitoring of the red cell parameters. The importance of inclusion of the red cell indices with special focus on $\mathrm{MCV}$ in all routine $\mathrm{CBC}$ reports is once again stressed through this study. Diagnosis of anemia in dengue patients is also important to prevent the spread of dengue by isolation. Iron supplementation of susceptible individuals could reduce dengue transmission in endemic areas.

\section{Acknowledgements}

We would like to acknowledge the support of the technical staff.

\section{Funding}

None

\section{Competing Interests}

None declared

\section{Reference}

1. WHO Guidelines Approved by the Guidelines Review Committee. Dengue: guidelines for diagnosis, treatment, prevention and control: new edition. Geneva: World Health Organization; 2009

2. Mutheneni SR, Morse AP, Caminade C, Upadhyayula SM Dengue burden in India: recent trends and importance of climatic parameters.Emerging microbes \& infections 2017;6(8):70. doi:10.1038/emi.2017.57
3. Balarajan Y, Ramakrishnan U, Ozaltin E, Shankar AH, Subramanian SV Anaemia in low-income and middleincome countries. Lancet 2011;378(9809):2123-35. doi:10.1016/S0140-6736(10)62304-5

4. Nutritionalanaemias:tools foreffectivepreventionandcontrol. Geneva: World Health Organization; 2017 (http://apps.who. int/iris/bitstream/10665/259425/1/9789241513067-eng.pdf, accessed 15 January 2018).

5. National Health Policy 2017. New Delhi: Ministry of Health and Family Welfare, Government of India; 2017 (http:// cdsco.nic.in/writereaddata/National-Health-Policy.pdf, accessed 15 January 2018).

6. WHO UNICEF and UNU Iron Deficiency Anaemia: Assessment, Prevention and Control, A Guide for Programme Managers, WHO, UNICEF, UNU, Geneva, Switzerland,2001, （http://www.who.int/nutrition/ publications/micronutrients/anaemia_iron_deficiency/ WHO_NHD_01.3/en/index.html, accessed 22 oct 2019).

7. Martina BE, Koraka P, Osterhaus AD Dengue virus pathogenesis: an integrated view. Clin Microbiol Rev. 2009;22(4):564-581. doi: 10.1128/CMR.00035-09.

8. SurveySoftware-The survey system[Internet]. Survey Software-Questionnire Software-Electronic Survey Software-The survey system;creative research systems;2012[cited 2019 Oct22].Available from: http:// www.surveysystem.com/

9. Ganeshkumar P, Murhekar MV, Poornima V, Saravanakumar $\mathrm{V}$, Sukumarn K Dengue infection in India: A systemic review and meta-analysis. PLOS Neglected Tropical Diseases 2018;12(7):e0006618.

10. Mogra G, Ghildiyal RG, Mohanlal S Classification and study of the clinico- hematological profile of patients with dengue fever in the pediatric age group. Int J Contemp Pediatr 2016;3:1405-10.

11. Chaloemwong J, Tantiworawit A, Rattanathammeethee T, Hantrakool S, Chaiadisakshopa C, Rattarittmrong E, Norasetthada L Useful clinical features and hematological parameters for the diagnosis of dengue infection in patients with acute febrile illness: a retrospective study. BMC Hematol 2018;18:20. doi: 10.1186/s12878-018-0116-1

12. Martina BE, Koraka $\mathrm{P}$, Osterhaus AD Dengue virus pathogenesis: an integrated view. Clin Microbiol Rev. 2009;22(4):564-81.

13. Ralapanawa U, Alawattegama ATM, Gunrathne M, Tennakoon S, Kularatne SAM, Jayalath S Value of peripheral blood count for dengue severity prediction. BMC Res Notes 2018;11(1):400.

14. Ramandeep K, Babita, Promila S. Heamtological and Biochemical Changes in Dengue Fever, Int J Pharm Sci Inv.2014; 3 (5):01-05

15. Shamsunder Khatroth. A Study on Clinical and Hematological Profile of Dengue Fever in a Tertiary Care Hospital. IAIM 2017;4(8):96-102. 
16. Meena KC, Jelia S, Meena S, Arif M, Ajmera D, Jatav VS A study of hematological profile in dengue fever at a tertiary care center, Kota Rajasthan. Int J Adv Med. 2016; 3(3):621-624.

17. Dongre T, Karmarkar P. Hematological Parameters and Its Utility in Dengue-A Prospestive Study. IOSR Journal of Dental and Medical Sciences, 2015;14(2):31-34

18. Mehta TK, Parul DS. Evaluation of Recent WHO Classification (2009) for Assessment of Dengue Disease Severity. Int.J Curr Microbiol App Sci 2015;4(9):755-765

19. Azin FR, Gonçalves RP, Pitombeira MH, Lima DM, Castelo Branco. Dengue: profile of hematological and biochemical dynamics. Rev Bras Hematol Hemoter. 2012;34(1):36-41

20. Sharma JB, Meenakshi S, Anemia in Pregnancy. JIMSA 2010;23(4):253-60

21. Scott BH, Lan N T, Myint TT, Shwe TN, Nisalak A, Kalyanarooj S, et al. Dengue Hemorrhagic Fever in Infants: Research Opportunities Ignored Emerging Infectious Diseases 2002;12(8):1474-79

22. Zhu Y, Tong L, Kaixiao N, Itsanun W, Peng S, Qingqing L, et al. Host serum iron modulates dengue virus acquisition by mosquitoes Nat Microbiol 2019; 1. doi: 10.1038/s41564019-0555-x.

*Corresponding author:

Dr. Idrees Akhtar Afroze, 11-3-956, Opposite Glory cinema, New Mallepally, Hyderabad-500001 INDIA

Phone: +91 9849283875

Email: idreesakhtarafroze@gmail.com

Financial or other Competing Interests: None. 